\title{
BMJ Open Longitudinal study of occupational noise exposure and joint effects with job strain and risk for coronary heart disease and stroke in Swedish men
}

\author{
Helena Pernilla Eriksson, ${ }^{1}$ Eva Andersson, ${ }^{1}$ Linus Schiöler, ${ }^{2}$ Mia Söderberg, ${ }^{2}$ \\ Mattias Sjöström, ${ }^{3,4}$ Annika Rosengren, ${ }^{5}$ Kjell Torén ${ }^{1,2}$
}

To cite: Eriksson HP, Andersson E, Schiöler L, et al. Longitudinal study of occupational noise exposure and joint effects with job strain and risk for coronary heart disease and stroke in Swedish men. BMJ Open 2018;8:e019160. doi:10.1136/ bmjopen-2017-019160

- Prepublication history for this paper is available online. To view these files, please visit the journal online (http://dx.doi org/10.1136/bmjopen-2017019160).

Received 15 August 2017 Revised 25 January 2018 Accepted 9 February 2018

Check for updates

${ }^{1}$ Department of Occupational and Environmental Medicine, Sahlgrenska University Hospital, Gothenburg, Sweden

${ }^{2}$ Section of Occupational and Environmental Medicine Institute of Medicine,

Sahlgrenska Academy, University of Gothenburg, Gothenburg, Sweden

${ }^{3}$ Department of Public Health Sciences, Karolinska Institutet, Stockholm, Sweden

${ }^{4}$ Institute of Environmental Medicine, Karolinska Institutet, Stockholm, Sweden

${ }^{5}$ Department of Molecular and Clinical Medicine, Institute of

Medicine, Sahlgrenska Academy, University of Gothenburg, Gothenburg, Sweden

Correspondence to Dr Helena Pernilla Eriksson; helena.eriksson@amm.gu.se

\section{ABSTRACT}

Objectives The aims were to investigate whether occupational noise increased the risk for coronary heart disease (CHD) and stroke and to elucidate interactions with stressful working conditions in a cohort of Swedish men. Design This is a prospective cohort study on CHD and stroke in Swedish men followed until death, hospital discharge or until 75 years of age, using Swedish national registers on cause of death and hospital discharges. Baseline data on occupation from 1974 to 1977 were used for classification of levels of occupational noise and job demand-control. Cox regression was used to analyse HRs for $\mathrm{CHD}$ and stroke.

Setting Swedish men born in 1915-1925.

Primary and secondary outcome measures $\mathrm{CHD}$ and stroke.

Participants The participants of the study were men from the Primary Prevention Study, a random sample of 10000 men born in 1915-1925 in Gothenburg. Subjects with CHD or stroke at baseline or were not employed were excluded. The remaining subjects with complete baseline data on occupation, weight, height, hypertension, diabetes, serum cholesterol and smoking constituted the study sample (5753 men).

Results There was an increased risk for $\mathrm{CHD}$ in relation to noise levels $75-85 \mathrm{~dB}(\mathrm{~A})$ and $>85 \mathrm{~dB}(\mathrm{~A})$ compared with $<75 \mathrm{~dB}(\mathrm{~A})$ (HR $1.15,95 \% \mathrm{Cl} 1.01$ to 1.31 , and HR 1.27, $95 \% \mathrm{Cl} 0.99$ to 1.63 , respectively). Exposure to noise peaks also increased the risk for CHD ( $\mathrm{HR} 1.19,95 \% \mathrm{Cl}$ 1.03 to 1.38). Among those with high strain (high demands and low controll) combined with noise $>75 \mathrm{~dB}(\mathrm{~A})$, the risk for CHD further increased (HR 1.80, 95\% $\mathrm{Cl} 1.19$ to 2.73). There was no significantly increased risk for stroke in any noise category.

Conclusions Exposure to occupational noise was associated with an increased risk for $\mathrm{CHD}$ and the risk further increased among those with concomitant exposure to high strain. None of the analysed variables were related to increased risk for stroke.

\section{INTRODUCTION}

Cardiovascular diseases are common diseases in Sweden as in most countries. In 2016, 25700 persons suffered from acute myocardial
Strengths and limitations of this study

This is a longitudinal cohort study with long-term follow-up, which strengthens the results.

- Data were retrieved from the national mortality register and hospital discharge register with high coverage, which increases the validity.

- Noise exposure was classified through a job-exposure matrix but no individual measurements of noise were performed.

- There were only men in the cohort, which limits the generalisability.

infarction and $25 \%$ of these died within 28 days. ${ }^{1}$ In the same year, stroke occurred in 26500 persons, and of these $26 \%$ died within 28 days. $^{2}$

Exposure to noise is frequent in many workplaces, and health effects especially hearing disorders have been investigated for decades. ${ }^{3}$ In addition to effects on hearing, there are studies indicating that occupational exposure to noise may increase the risk for cardiovascular diseases, such as hypertension, coronary heart disease and stroke. ${ }^{4-7}$ The evidence is, however, rather weak, especially on the association with stroke, where there is a conspicuous lack of prospective studies. ${ }^{8}$ Regarding coronary heart disease and occupational exposure to noise, the few available longitudinal studies seem to favour an association. In a Canadian study of 30000 lumber mill workers, there was an increased risk of fatal acute myocardial infarction both in relation to the duration of employment and to noise levels. ${ }^{9}$ A Finnish study showed an increased risk for coronary heart disease in relation to continuous noise exposure exceeding $85 \mathrm{~dB}(\mathrm{~A})$; impulse noise also showed an increased risk. ${ }^{10}$

There are few studies and there is conflicting evidence whether occupational exposure to noise increases the risk for 
stroke. $^{8}$ A Japanese study ${ }^{11}$ showed an increased HR for intracerebral bleeding but not for ischaemic stroke. A Danish study ${ }^{12}$ of more than 200000 workers did not show an increased risk for stroke in relation to occupational noise exposure. In an Australian study of 2942 subjects, there was a significant association between the incidence of stroke and those exposed to very high levels of noise. ${ }^{13}$

In a study from 2016 based on noise exposure and occurrence of stroke in the US general population, there was no statistically significant association between exposure to noise and stroke after adjusting for sociodemographics, lifestyle and comorbidity. ${ }^{14}$

The mechanisms regarding occupational noise exposure and risk for cardiovascular disease are not clear. Environmental noise and the mechanisms behind the increased risk for cardiovascular disease have been studied to a larger extent. ${ }^{15}$ Noise exposure activates the autonomic and endocrine systems, and the blood pressure increases, the heart rate is altered and stress hormones are released. Chronic noise exposure can affect blood pressure, blood glucose, blood lipids and viscosity, leading to an increased risk for cardiovascular disease. ${ }^{15}$

Exposure to workplace stress is often evaluated according to the job demand-control model. ${ }^{16}$ Throughout the literature, high strain, the combination of high demands and low control, has been linked to ill-health, primarily coronary heart disease. ${ }^{17}$ A recent meta-analysis of 13 studies concluded that the association with coronary heart disease was rather small but consistent (HR 1.23). ${ }^{18}$ However, there seems to be an interaction between job strain and occupational noise. ${ }^{19}$

The aims of the present study were to investigate whether occupational exposure to noise increased the risk for coronary heart disease and stroke, and to elucidate potential interactions with stressful psychosocial work conditions based on the job demand-control model in a longitudinal general population study.

\section{METHODS}

\section{Study population}

The Primary Prevention Study is a cohort study obtained from a general population sample, as previously described..$^{20}$ The source population comprised 10000 men, a random third of all men living in Gothenburg born between 1915 and 1925, of whom 7494 participated in screening examinations between January 1970 and March 1973. Three years later, 1974-1977, a clinical follow-up investigation was performed, where 7133 men participated. In the present study we used the follow-up data as our baseline since they include occupational data and information about age, body mass index (BMI) (BMI is the weight in kilograms divided by the square of the body height in metres), serum cholesterol level, systolic blood pressure, diastolic blood pressure, physician-diagnosed diabetes (yes/no), physician-diagnosed hypertension (yes/no), coronary heart disease (yes/no) or stroke (yes/no), and smoking, as previously described. ${ }^{22}$
Subjects with coronary heart disease or stroke at baseline $(n=329)$ and subjects not employed $(n=730)$ were excluded, leaving 6074. The remaining subjects with complete baseline data on occupation, weight, height, hypertension, diabetes, serum cholesterol and smoking constituted the study sample $(n=5753)$, with an age range of 50-59 years (table 1 ). All participants gave their informed consent to participate in the study.

To assess occupational noise exposure, a previously developed job-exposure matrix (JEM) on noise was applied. ${ }^{23}$ The noise JEM is based on 145 measurement reports and a total of 569 measurements on 129 unique job families. It classifies 321 occupations based on the Nordisk yrkesklassificering (NYK) $-85 / 90$ according to noise levels and peak levels. The noise JEM classification covers the period from 1970 to 2004 in 5-year intervals.

The noise levels were categorised into three different levels in the JEM: low, $<75 \mathrm{~dB}(\mathrm{~A})$; medium, $75-85 \mathrm{~dB}(\mathrm{~A})$; and high, $>85 \mathrm{~dB}(\mathrm{~A})$. There was also an assessment of whether there was a high risk of peak level noise exposure and the categories: 'Noise peaks likely' ('Yes, for sure' combined with 'Yes, probably') and 'Noise peaks maybe' were compared with the category 'Noise peaks unlikely'.

To assess the psychosocial workplace exposure, we used a previously published and used JEM. ${ }^{24} 25$ This psychosocial JEM provides separate estimates of job demand and control for 261 occupations separated into gender and age (25-44 and 45-74), as previously described. ${ }^{22}{ }^{26} \mathrm{Job}$ demands and decision latitude were explored with four items each, and all subjects were assigned a certain score based on occupation and age in this psychosocial JEM. Using the median of the distribution as cut-off, which is standard procedure, demand and control were dichotomised as high or low. The participants were then allocated into four categories: high strain (high demand-low control), active (high demand-high control), passive (low demand-low control) and low strain (low demand-high control).

Based on Sweden's unique personal identification numbers, participants were followed from the date of their baseline examination until death, until hospital discharge or until 75 years of age, using the Swedish national register on cause of death and the Swedish hospital discharge register.

All discharges from Gothenburg hospitals have been entered into the national register since 1970, with the exception of 1976. The outcomes were classified according to the International Classification of Diseases (ICD-8) code until 1986, ICD-9 was used from 1987 to 1996, and ICD-10 was used from 1997 onwards. Coronary heart disease was defined as 410-414 (ICD-8, ICD-9) and as I20-I25 (ICD-10) from the death register and as acute myocardial infarction 410 and I21 from the discharge register, respectively. Stroke events, including both ischaemic stroke and intracerebral bleeding, were defined as death or hospitalisation with ICD codes 431-438 (ICD-8, ICD-9) and I61-I69 (ICD-10). Each type of event was 


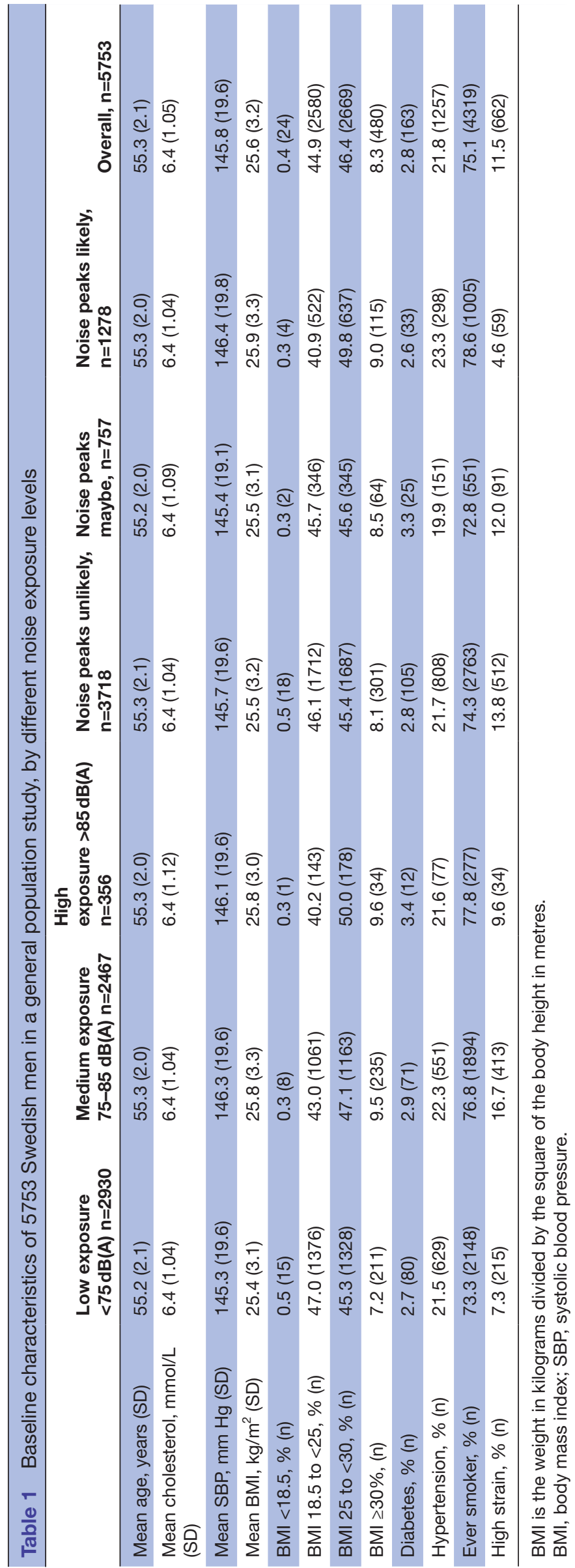

treated separately and only the first event of each type was used in the analysis.

\section{Statistical analysis}

Descriptive statistics are presented as percentages or mean values with SD. All analyses were performed using the SAS V.9.3 statistical package and R V.3.0.1. The material was analysed with Cox regression models using SAS (the PHREG procedure). The proportional hazards assumptions were investigated using tests and plots based on weighted residuals ${ }^{27}$ using the $\mathrm{R}$ package Survival. Proportional hazards assumptions were found reasonable except for the analysis of smoking and serum cholesterol, which we stratified for in the risk factor-adjusted models. Hospital care or mortality (whatever came first) from coronary heart disease or stroke was considered events, and time was measured as months since baseline. The observation period stopped at the age of 75. Analyses were also performed restricted to subjects younger than 65 years. In the crude models, HRs and $95 \%$ CI were calculated using the occupational noise exposure and age as explanatory variables. Tests for trend were performed by including the covariate as a continuous variable.

In the risk factor-adjusted models, we adjusted for ever-smoking (yes/no), cholesterol (quartiles), history of diabetes (yes/no), hypertension (yes/no) and BMI $(<18.5,25$ to $<30$ and $\geq 30$ compared with 18.5 to $<25)$. The interaction between occupational noise exposure and high strain was analysed separately; here the noise exposure was aggregated into $<75$ and $>75 \mathrm{~dB}$ (A) to gain power. The population was divided into two groupssubjects exposed to high strain versus others not exposed to high strain-and HRs were calculated. Wald test was used to test the interaction.

A sensitivity analysis was performed restricted to the subjects without hypertension and diabetes, potential mediators for coronary heart disease.

\section{RESULTS}

During the follow-up period of a total of 94222 personyears (mean years per person: 16.4), there were 1004 events of coronary heart disease (table 2). The Cox regression models adjusted for age showed an increased HR for coronary heart disease in relation to medium levels (HR 1.15, 95\% CI 1.01 to 1.31) and high levels (HR $1.27,95 \%$ CI 0.99 to 1.63 ) of occupational noise exposure (table 2) and a positive trend.

Exposure to noise peaks also increased the risk for coronary heart disease (HR 1.19, 95\% CI 1.03 to 1.38). In the risk factor-adjusted models, all estimates were slightly diminished, but on noise peaks the statistical significance remained. When the risk for coronary heart disease was restricted to subjects younger than 65 years, the risk estimates increased, but due to lack of power the CIs turned wider and included unity.

When analysing the cohort without the subjects with hypertension and diabetes at baseline $(n=4400)$, the 
Open Access

Table 2 Incidence and HRs with Cls for coronary heart disease and stroke in relation to exposure to occupational noise among all men $(n=5753)$

\begin{tabular}{|c|c|c|c|}
\hline & $\begin{array}{l}\text { Events per } 1000 \text { observation } \\
\text { years ( } n \text { events) }\end{array}$ & Age-adjusted HR $(95 \% \mathrm{Cl})$ & $\begin{array}{l}\text { Risk factor-adjusted }{ }^{*} \text { HR } \\
(95 \% \mathrm{Cl})\end{array}$ \\
\hline Coronary heart disease, all & $10.7(1004)$ & & \\
\hline Low noise, $<75 \mathrm{~dB}(\mathrm{~A})$ & $9.8(480)$ & 1.00 (ref) & 1.00 (ref) \\
\hline Medium noise, $75-85 \mathrm{~dB}(\mathrm{~A})$ & $11.4(453)$ & 1.15 (1.01 to 1.31$)$ & 1.13 (0.99 to 1.28$)$ \\
\hline High noise, $>85 \mathrm{~dB}(\mathrm{~A})$ & $12.4(71)$ & 1.27 (0.99 to 1.63 ) & 1.22 (0.95 to 1.56$)$ \\
\hline$P$ value for trend & & $\mathrm{P}=0.01$ & $P=0.03$ \\
\hline Noise peaks unlikely & $10.2(622)$ & 1.00 (ref) & 1.00 (ref) \\
\hline Noise peaks maybe & $10.6(135)$ & 1.05 (0.87 to 1.26$)$ & 1.04 (0.86 to 1.25$)$ \\
\hline Noise peaks likely & $12.1(247)$ & 1.19 (1.03 to 1.38$)$ & 1.16 (1.00 to 1.34$)$ \\
\hline$P$ value for trend & & $\mathrm{P}=0.03$ & $P=0.06$ \\
\hline $\begin{array}{l}\text { Coronary heart disease, } \\
\text { subjects } \leq 65 \text { years }\end{array}$ & $7.5(375)$ & & \\
\hline Low noise, $<75 \mathrm{~dB}(\mathrm{~A})$ & $6.7(174)$ & 1.00 (ref) & 1.00 (ref) \\
\hline Medium noise, $75-85 \mathrm{~dB}(\mathrm{~A})$ & $8.2(172)$ & 1.20 (0.97 to 1.48$)$ & 1.17 (0.94 to 1.44$)$ \\
\hline High noise, $>85 \mathrm{~dB}(\mathrm{~A})$ & $9.4(29)$ & 1.38 (0.93 to 2.05$)$ & 1.30 (0.88 to 1.93$)$ \\
\hline$P$ value for trend & & $P=0.04$ & $P=0.09$ \\
\hline Noise peaks unlikely & $7.5(243)$ & 1.00 (ref) & 1.00 (ref) \\
\hline Noise peaks maybe & $6.1(41)$ & 0.82 (0.58 to 1.13$)$ & 0.82 (0.59 to 1.14$)$ \\
\hline Noise peaks likely & $8.3(91)$ & $1.11(0.87$ to 1.41$)$ & 1.07 (0.84 to 1.36$)$ \\
\hline$P$ value for trend & & $P=0.60$ & $\mathrm{P}=0.81$ \\
\hline Stroke, all & $5.4(517)$ & & \\
\hline Low noise, $<75 \mathrm{~dB}(\mathrm{~A})$ & $5.3(262)$ & 1.00 (ref) & 1.00 (ref) \\
\hline Medium noise, $75-85 \mathrm{~dB}(\mathrm{~A})$ & $5.4(220)$ & 1.02 (0.85 to 1.22$)$ & 1.01 (0.84 to 1.21$)$ \\
\hline High noise, $>85 \mathrm{~dB}(\mathrm{~A})$ & $6.0(35)$ & 1.16 (0.82 to 1.65$)$ & $1.12(0.79$ to 1.59$)$ \\
\hline$P$ value for trend & & $P=0.51$ & $P=0.65$ \\
\hline Noise peaks unlikely & $5.4(336)$ & 1.00 (ref) & 1.00 (ref) \\
\hline Noise peaks maybe & $4.5(59)$ & 0.83 (0.63 to 1.10$)$ & 0.84 (0.63 to 1.10$)$ \\
\hline Noise peaks likely & $5.8(122)$ & 1.08 (0.88 to 1.33$)$ & 1.06 (0.86 to 1.30$)$ \\
\hline$P$ value for trend & & $P=0.65$ & $P=0.82$ \\
\hline Stroke, subjects $\leq 65$ years & $2.7(138)$ & & \\
\hline Low noise, $<75 \mathrm{~dB}(\mathrm{~A})$ & $2.8(73)$ & 1.00 (ref) & 1.00 (ref) \\
\hline Medium noise, $75-85 \mathrm{~dB}(\mathrm{~A})$ & $2.5(54)$ & 0.89 (0.63 to 1.27$)$ & 0.90 (0.63 to 1.28$)$ \\
\hline High noise, $>85 \mathrm{~dB}(\mathrm{~A})$ & $3.5(11)$ & 1.26 (0.67 to 2.37$)$ & 1.23 (0.65 to 2.32$)$ \\
\hline$P$ value for trend & & $P=0.97$ & $\mathrm{P}=0.98$ \\
\hline Noise peaks unlikely & $2.7(89)$ & 1.00 (ref) & 1.00 (ref) \\
\hline Noise peaks maybe & $1.8(12)$ & 0.65 (0.36 to 1.19$)$ & 0.66 (0.36 to 1.20$)$ \\
\hline Noise peaks likely & $3.3(37)$ & $1.23(0.84$ to 1.81$)$ & 1.23 (0.83 to 1.80$)$ \\
\hline$P$ value for trend & & $\mathrm{P}=0.46$ & $P=0.47$ \\
\hline
\end{tabular}

${ }^{*}$ Age in years, baseline body mass index $(<18.5,25$ to $<30$ and $\geq 30$ compared with 18.5 to $<25)$, baseline diabetes, hypertension and by stratification never/ever smoker and cholesterol in quartiles.

Ref, reference.

HR for coronary heart disease was 1.20 (95\% CI 1.03 to $1.41)$ in relation to a medium level of noise exposure and 1.49 (95\% CI 1.11 to 1.99 ) in relation to a high level of noise exposure, and for the subjects with likely exposure to noise peaks the HR was 1.30 (95\% CI 1.09 to 1.55$)$.

In the follow-up period, there were 517 stroke events. There was no increased risk for stroke in any of the 
Table 3 Interaction between occupational noise exposure and high strain

\begin{tabular}{|c|c|c|c|c|}
\hline & \multicolumn{2}{|l|}{ Age-adjusted HR (95\% Cl) } & \multicolumn{2}{|c|}{ Risk factor-adjusted* HR $(95 \% \mathrm{Cl})$} \\
\hline & High strain (n events) & $\begin{array}{l}\text { Not high strain ( } \mathrm{n} \\
\text { events) }\end{array}$ & High strain & Not high strain \\
\hline Low noise, $<75 \mathrm{~dB}(\mathrm{~A})$ & 1.00 (ref) $(n=29)$ & 1.00 (ref) $(n=451)$ & 1.00 (ref) & 1.00 (ref) \\
\hline $\begin{array}{l}\text { Medium and high } \\
\text { noise, } \geq 75 \mathrm{~dB}(\mathrm{~A})\end{array}$ & $1.80(1.19$ to 2.73$)(n=99)$ & $\begin{array}{l}1.10(0.96 \text { to } 1.25) \\
(n=425)\end{array}$ & $1.73(1.14$ to 2.61$)$ & $1.08(0.94$ to 1.23$)$ \\
\hline Noise peaks unlikely & 1.00 (ref) $(\mathrm{n}=92)$ & 1.00 (ref) $(\mathrm{n}=530)$ & 1.00 (ref) & 1.00 (ref) \\
\hline Noise peaks maybe & $1.39(0.88$ to 2.19$)(n=23)$ & $\begin{array}{l}1.00(0.81 \text { to } 1.22) \\
(n=112)\end{array}$ & 1.45 (0.91 to 2.29$)$ & $0.99(0.80$ to 1.21$)$ \\
\hline Noise peaks likely & $1.25(0.70$ to 2.23$)(n=13)$ & $\begin{array}{l}1.20(1.03 \text { to } 1.40) \\
(n=234)\end{array}$ & $1.29(0.72$ to 2.31$)$ & $1.16(0.99$ to 1.35$)$ \\
\hline Low noise, $<75 \mathrm{~dB}(\mathrm{~A})$ & 1.00 (ref) $(n=17)$ & 1.00 (ref) $(n=245)$ & 1.00 (ref) & 1.00 (ref) \\
\hline $\begin{array}{l}\text { Medium and high } \\
\text { noise, } \geq 75 \mathrm{~dB}(\mathrm{~A})\end{array}$ & $1.33(0.76$ to 2.33$)(n=43)$ & $\begin{array}{l}1.01(0.84 \text { to } 1.21) \\
(n=212)\end{array}$ & 1.38 (0.79 to 2.43$)$ & $0.98(0.82$ to 1.19$)$ \\
\hline$P$ value for interaction & $P=0.35$ & & $P=0.27$ & \\
\hline Noise peaks unlikely & 1.00 (ref) $(n=47)$ & 1.00 (ref) $(\mathrm{n}=289)$ & 1.00 (ref) & 1.00 (ref) \\
\hline Noise peaks maybe & $0.68(0.29$ to 1.60$)(n=6)$ & $\begin{array}{l}0.86(0.64 \text { to } 1.15) \\
(n=53)\end{array}$ & 0.70 (0.30 to 1.65$)$ & 0.85 (0.64 to 1.15$)$ \\
\hline Noise peaks likely & $1.44(0.65$ to 3.19$)(n=7)$ & $\begin{array}{l}1.07(0.87 \text { to } 1.33) \\
(n=115)\end{array}$ & 1.34 (0.61 to 2.98$)$ & $1.04(0.84$ to 1.30$)$ \\
\hline$P$ value for interaction & $P=0.66$ & & $P=0.74$ & \\
\hline
\end{tabular}

$\mathrm{HR}$ with $\mathrm{Cl}$ for coronary heart disease and stroke in subjects exposed to high strain versus not exposed to high strain in relation to exposure to occupational noise among all men $(n=5753)$.

${ }^{*}$ Age in years, baseline body mass index $(<18.5,25$ to $<30$ and $\geq 30$ compared with 18.5 to $<25)$, baseline diabetes, hypertension and by stratification never/ever smoker and cholesterol in quartiles.

ref, reference.

exposure strata, medium levels, high levels or peaks of noise exposure (table 2 ).

In table 3, risk estimates for occupational noise exposure are outlined in the different groups of high strain and not high strain. Among those who were classified as having high strain (high demands and low control) and occupational noise exposure $>75 \mathrm{~dB}(\mathrm{~A})$, the risk for coronary heart disease further increased (HR 1.80, 95\% CI 1.19 to 2.73 , age-adjusted and risk factor-adjusted: HR $1.73,95 \%$ CI 1.14 to 2.61 ). The interaction analyses on stroke were negative.

\section{DISCUSSION}

The present study suggests an increased risk for coronary heart disease in relation to both continuous noise and peaks of occupational exposure to noise; concomitant exposure to high strain further increased the risk of coronary heart disease. There was no increased risk for stroke in relation to occupational noise exposure.

This study has several advantages, such as its external validity because a general population sample with a long period of follow-up was available with near-complete follow-up. The use of a national mortality register and hospital discharge register with high coverage further increased the validity of the results.

However, there are also several limitations. On stroke outcome, the restricted number of cases and lack of CT during early follow-up did not allow for analyses of subtypes of stroke, so there may be a misclassification. Stroke comprises different subtypes such as ischaemic stroke and intracerebral bleeding, and sometimes also subarachnoidal bleeding is included in the stroke concept. All those clinical subtypes of stroke may be related to different risk factors. In a Japanese study ${ }^{11}$ comprising 14568 subjects, the HR for intracerebral bleeding was 2.1 (1.01 to 4.4) and the HR for ischaemic stroke was 1.7 (0.7 to 4.1$)$. The noise levels were self-reported and the outcome was based on population registries.

There were no individual measurements of noise levels for the participants; instead the assigned exposure was estimated from average levels in similar workplaces using a previously developed noise JEM. In a Swedish 
case-control study where the subjects' occupational noise exposure was classified using the same JEM as in our study, there was an increased OR for myocardial infarction for occupational noise exceeding $75 \mathrm{~dB}(\mathrm{~A})$, but with adjustments for age, sex, smoking, socioeconomic status and air pollution the risk decreased and became insignificant. ${ }^{19}$ The assessment of noise exposure and job strain based on job exposure matrices may display less bias than self-reports. But there may be a considerable non-differential misclassification of the exposure estimates causing attenuation of the risk estimates.

We did not have information on individual use of hearing protection, but most of the men in the cohort retired from work at the latest at the end of the 1980s, and in Sweden the use of hearing protection became commonly used first at that time. It is not likely that there has been a frequent use of hearing protection among the subjects. In addition, we did not have information on coexposures such as dust, fumes or residential noise. Of importance is also that the study comprises only men, which limits its external validity.

We had access to individual baseline data on smoking habits, BMI, diabetes, hypertension and cholesterol; this made it possible to have control of interactions and confounding. An 18-year follow-up of 6005 men from the Helsinki Heart Study, where they also had access to register-based outcome and individual data on smoking, BMI and blood pressure, showed an increased risk $(1.48,95 \%$ CI 1.28 to 1.71 ) of coronary heart disease in relation to continuous noise exposure exceeding $85 \mathrm{~dB}(\mathrm{~A})$; exposure to impulse noise showed similar risk estimates. ${ }^{10}$

We present risk factor-adjusted models, but we also present simple only age-adjusted models, since risk factors can be mediators. A sensitivity analysis was also performed, and a significantly increased risk of coronary heart disease remained when excluding the subjects with baseline hypertension and diabetes. We did not have socioeconomic status and adjusting for it could implicate an overadjustment; the exposure was based on occupations, which usually comprise the socioeconomic position.

We used the job held at the age of 50 years, which probably in most cases reflects the longest held job. We also analysed the risk below 65 years and found higher risks in working age. This may reflect that the risk of coronary heart disease is dependent on current noise exposure and that the risk may decrease after termination of the work, as observed in a Canadian study ${ }^{9}$ where the highest risk was found among those who were currently working and had been employed 20 years or more, with relative risks between 2.0 and 4.0.

Our results showed an interaction between noise and high strain. However there are also reported interactions between job strain and lifestyle factors, such as smoking, being obese or reporting low physical activity. ${ }^{28}$ We have adjusted for smoking and BMI, but not physical activity, as we do not have this information.

Our results on coronary heart disease corroborate earlier studies, giving further evidence for a causal relation between occupational noise exposure and increased risk for coronary heart disease. ${ }^{4-7}$ We also support the findings by Selander $e t a l^{19}$ that high strain (high demand/ low control) further increased the risk for coronary heart disease. The results from the present study indicate that exposure to occupational noise does not increase the risk for stroke, in accordance with previous studies. ${ }^{12}{ }^{14}$ This could be due to power, suboptimal classification of the different subtypes of stroke or perhaps that stroke has a different pattern of occupational risk factors compared with coronary heart disease.

\section{CONCLUSIONS}

Exposure to occupational noise increased the risk of coronary heart disease. There was no increased risk for stroke in any of the noise exposure categories. There were indications of an interaction between noise exposure and work-related strain, and further studies are needed to elucidate patterns of interactions between different occupational risk factors.

Contributors AR, KT and EA conceptualised, designed and supervised the study. HPE helped to conceive the study and drafted the manuscript. MaS has participated in developing the job-exposure matrix on noise. LS performed the statistical analyses. MiS critically revised the manuscript. All authors were responsible for the drafting and final approval of the manuscript.

Funding The study was funded by the Swedish Research Council (VR) [2013-5187 (SIMSAM), 2013-4236], the Swedish Research Council for Health, Working Life and Welfare (FORTE), and the Swedish Heart and Lung Foundation [2015-0438].

Competing interests None declared.

Patient consent Not required.

Ethics approval Ethics approval by the Ethics Committee for Medical Research at the University of Gothenburg.

Provenance and peer review Not commissioned; externally peer reviewed.

Data sharing statement This is a large general population study that has been followed for many years. There are unpublished data in the data set. Scientific cooperation around this study is possible by contacting the corresponding author.

Open Access This is an Open Access article distributed in accordance with the Creative Commons Attribution Non Commercial (CC BY-NC 4.0) license, which permits others to distribute, remix, adapt, build upon this work non-commercially, and license their derivative works on different terms, provided the original work is properly cited and the use is non-commercial. See: http://creativecommons.org/ licenses/by-nc/4.0/

(C) Article author(s) (or their employer(s) unless otherwise stated in the text of the article) 2018. All rights reserved. No commercial use is permitted unless otherwise expressly granted.

\section{REFERENCES}

1. Socialstyrelsen. Statistik om stroke, korta fakta. http://www. socialstyrelsen.se/statistik/statistikefteramne/hjartinfarkter

2. Socialstyrelsen. Statistik om stroke, korta fakta. http://www. socialstyrelsen.se/statistik/statistikefteramne/stroke

3. Lie A, Skogstad M, Johannessen HA, et al. Occupational noise exposure and hearing: a systematic review. Int Arch Occup Environ Health 2016;89:351-72.

4. Sbihi H, Davies HW, Demers PA. Hypertension in noise-exposed sawmill workers: a cohort study. Occup Environ Med 2008;65:643-6.

5. Skogstad M, Johannessen HA, Tynes T, et al. Systematic review of the cardiovascular effects of occupational noise. Occup Med 2016;66:10-16. 
6. Theorell T, Jood K, Järvholm LS, et al. A systematic review of studies in the contributions of the work environment to ischaemic heart disease development. Eur J Public Health 2016;26:470-7.

7. Dzhambov AM, Dimitrova DD. Occupational noise and ischemic heart disease: A systematic review. Noise Health 2016;18:167-77.

8. Kolstad HA, Stokholm ZA, Hansen AM, et al. Whether noise exposure causes stroke or hypertension is still not known. BMJ 2013;347:f7444.

9. Davies HW, Teschke K, Kennedy SM, et al. Occupational exposure to noise and mortality from acute myocardial infarction. Epidemiology 2005;16:25-32.

10. Virkkunen H, Kauppinen T, Tenkanen L. Long-term effect of occupational noise on the risk of coronary heart disease. Scand J Work Environ Health 2005;31:291-9.

11. Fujino $\mathrm{Y}$, Iso $\mathrm{H}$, Tamakoshi $\mathrm{A}$. JACC study group. A prospective cohort study of perceived noise exposure at work and cerebrovascular diseases among male workers in Japan. J Occup Health 2007;49:382-8.

12. Stokholm ZA, Bonde JP, Christensen $\mathrm{KL}$, et al. Occupational noise exposure and the risk of stroke. Stroke 2013;44:3214-6.

13. Gopinath B, Thiagalingam A, Teber E, et al. Exposure to workplace noise and the risk of cardiovascular disease events and mortality among older adults. Prev Med 2011;53:390-4.

14. Dzhambov AM, Dimitrova DD, Tokmakova MP. Association between self-reported occupational noise and the prevalence of stroke: Secondary analysis of the National Health Interview Survey, 2014. Noise Control Eng J 2016;64:779-88.

15. Basner M, Babisch W, Davis A, et al. Auditory and non-auditory effects of noise on health. Lancet 2014;383:1325-32.

16. Karasek RA. Job demands, job decision latitude, and mental strain: implications for job redesign. Adm Sci Q 1979;24:285-308.

17. Eller $\mathrm{NH}$, Netterstrøm B, Gyntelberg F, et al. Work-related psychosocial factors and the development of ischemic heart disease: a systematic review. Cardiol Rev 2009;17:83-97.
18. Kivimäki M, Nyberg ST, Batty GD, et al. Job strain as a risk factor for coronary heart disease: a collaborative meta-analysis of individual participant data. Lancet 2012;380:1491-7.

19. Selander J, Bluhm G, Nilsson M, et al. Joint effects of job strain and road-traffic and occupational noise on myocardial infarction. Scand $J$ Work Environ Health 2013;39:195-203.

20. Wilhelmsen L, Berglund G, Elmfeldt D, et al. The multifactor primary prevention trial in Göteborg, Sweden. Eur Heart $J$ 1986;7:279-88.

21. Harmsen P, Lappas G, Rosengren A, et al. Long-term risk factors for stroke: twenty-eight years of follow-up of 7457 middle-aged men in Göteborg, Sweden. Stroke 2006;37:1663-7.

22. Torén K, Schiöler L, Söderberg M, et al. The association between job strain and atrial fibrillation in Swedish men. Occup Environ Med 2015;72:177-80.

23. Sjöström $M$, Lewné $M$, Alderling $M$, et al. A job-exposure matrix for occupational noise: development and validation. Ann Occup Hyg 2013;57:774-83.

24. Johnson JV, Stewart W, Hall EM, et al. Long-term psychosocial work environment and cardiovascular mortality among Swedish men. Am J Public Health 1996;86:324-31.

25. Fredlund P, Hallqvist J, Diderichsen F. Psykosocial yrkesexponeringsmatris. Arbete och Hälsa 2000;11:1-37. In Swedish.

26. Torén K, Schiöler L, Giang WK, et al. A longitudinal general population-based study of job strain and risk for coronary heart disease and stroke in Swedish men. BMJ Open 2014;4:e004355.

27. Grambsch PM, Therneau TM. Proportional hazards tests and diagnostics based on weighted residuals. Biometrika 1994;81:515-26.

28. Kivimäki M, Nyberg ST, Fransson El, et al. Associations of job strain and lifestyle risk factors with risk of coronary artery disease: a meta-analysis of individual participant data. CMAJ 2013;185:763-9. 